\title{
Leverage and the Financial Accelerator in a Liquidity Trap
}

\author{
By Karel Mertens and Morten O. Ravn*
}

The recent recession in the US saw an unusually large and persistent decline in output, low inflation and deflation, significant house price declines, and short term interest rates near zero. Much discussion of this episode has centered around financial markets and the high leverage positions at the onset of the recession. In this paper, we analyze the role of leverage in determining the properties of liquidity trap recessions.

Our theoretical framework extends the New Keynesian model in Karel Mertens and Morten O. Ravn (2010a) with real estate, nominal debt and financial frictions in the tradition of Nobuhiro Kiyotaki and John Moore (1997). As in Iacoviello (2005), there are savers (patient households) and borrowers (impatient entrepreneurs) who face a collateral constraint. The collateral is real estate which functions as housing for households and as a production input for entrepreneurs. Monetary policy is implemented as an interest rate rule that is subject to the zero lower bound.

The model displays global equilibrium indeterminacy and we study equilibria in which a credit crunch and liquidity trap recession occur after a self-fulfilling loss in confidence. During such episodes, debt and house price deflation act as important propagation mechanisms. We show that higher leverage (i) greatly deepens the liquidity trap recession and (ii) shrinks the set of pessimistic beliefs for which liquidity traps can arise. In particular, higher loan-tovalue ratios imply that only sufficiently persistent liquidity traps can arise in equilibrium. The latter effect however is small. The main consequence of financial innovation and deregulation leading to higher leverage may therefore have been stronger financial propagation in a liquidity trap recession.

* Mertens: Cornell University, 404 Uris Hall, Ithaca, NY 14853, km426@cornell.edu. Ravn: University College London, Drayton House, London WC1E 6BT, United Kingdom, m.ravn@ucl.ac.uk.

\section{The Model}

A large number of identical households derive utility from a composite consumption good, $c_{h}$, housing, $h_{h}$ and leisure, $1-n_{h}$, where $n_{h} \in$ $[0,1]$ is hours worked. They maximize lifetime utility

$$
\begin{aligned}
& E_{0} \sum_{t=0}^{\infty} \beta_{h}^{t} \ln \left(z_{h, t}\right)+\theta \frac{\left(1-n_{h, t}\right)^{1-\kappa}-1}{1-\kappa} \\
& z_{h, t}=\left(\rho^{1 / \zeta} h_{h, t}^{1-1 / \zeta}+c_{h, t}^{1-1 / \zeta}\right)^{1 /(1-1 / \zeta)}
\end{aligned}
$$

where $E_{0}$ is the expectation operator, $\beta_{h} \in$ $(0,1)$ and $\rho, \zeta, \theta, \kappa>0$. The flow budget constraint is

$$
\begin{aligned}
& P_{t} c_{h, t}+Q_{t} \Delta h_{h, t}+B_{h, t} /\left(1+i_{t}\right) \\
\leq & W_{t} n_{h, t}+B_{h, t-1}+\Gamma_{t}+T_{t}
\end{aligned}
$$

$P$ is the price of the composite consumption good. $B_{h}$ are nominal one period discount bonds purchased at price $1 /(1+i) . \quad Q$ is the price of real estate. Households own retail firms and receive dividends, $\Gamma$. $W$ is the nominal wage. $T$ denotes lump-sum transfers from the government. The households' problem is subject to a no-Ponzi condition and initial conditions for debt and housing.

A continuum of competitive entrepreneurs produce a wholesale good, $y^{w}$ according to the technology

$$
y_{t}^{w}=A h_{e, t-1}^{v} n_{e, t}^{1-v}
$$

where $A>0,0<v<1, n_{e}$ is labor input $h_{e}$ is commercial real estate. Entrepreneurs derive utility from consumption of the composite good, $c_{e, t}$ and maximize

$$
E_{0} \sum_{t=0}^{\infty} \beta_{e}^{t} \ln c_{e, t}
$$

We assume $\beta_{e} \in\left(0, \beta_{h}\right)$ such that entrepreneurs are less patient than households. As in 
Iacoviello (2005), nominal debt issues by entrepreneurs, $B_{e}$, are constrained by the collateral value of real estate assets:

$$
B_{e, t} \leq \mu E_{t}\left(Q_{t+1} h_{e, t}\right)
$$

Debt repayments in period $t+1$ cannot exceed a fraction $\mu \in[0,1)$ of the expected collateral value. In our experiments, the values of $\beta_{h}$ and loan-to-value $\mu$ are such that the borrowing constraint is always binding in equilibrium. The entrepreneurs' flow budget constraint is

$$
\begin{aligned}
& P_{t} c_{e, t}+Q_{t} \Delta h_{e, t}+W_{t} n_{e, t}+B_{e, t-1} \\
& \leq P_{t}^{w} y_{t}^{w}+B_{e, t} /\left(1+i_{t}\right)
\end{aligned}
$$

where $P^{w}$ is the price of wholesale goods.

Monopolistically competitive retailers, indexed by $i$, transform the wholesale good into differentiated final consumption goods. Retail goods prices $P_{i t}$ are staggered à la Calvo and $1-\xi$ is the probability that firms can reoptimize in any given period. The demand for retail goods is $y_{i t}=\left(P_{i t} / P_{t}\right)^{-\eta}\left(c_{h, t}+c_{e, t}\right)$ where $\eta>1$ and the price index is $P_{t}=\left(\int_{i} P_{i t}^{1-\eta} d i\right)^{1 /(1-\eta)}$.

Monetary policy is described by an interest rate rule subject to the zero lower bound

$$
1+i_{t}=\max \left(1,\left(1 / \beta_{h}\right) \pi_{t}^{\phi_{\pi}}\right)
$$

where $\phi_{\pi}$ is sufficiently large to satisfy local determinacy conditions in a zero inflation steady state. This rule implicitly assumes that the central bank pursues an objective of price stability. The government balances its budget period-byperiod.

We study symmetric rational expectations equilibria. Labor and credit market clearing requires $n_{h, t}=n_{e, t}, b_{h, t}=b_{e, t}$. The supply of housing is a constant $\vec{h}$ such that $h_{h, t}+h_{e, t}=\bar{h}$. Goods market clearing requires

$$
y_{t}=c_{e, t}+c_{h, t}=y_{t}^{w} / v_{t}
$$

where $y_{t}$ is aggregate output and $v_{t} \geq 1$ is a price dispersion term that evolves according to

$$
v_{t}=\xi \pi_{t}^{\eta} v_{t-1}+(1-\xi)\left(p_{t}^{*}\right)^{-\eta}
$$

Thomas J. Sargent and Neil Wallace (1975) show that under an interest rate rule ratio- nal expectations monetary models can display equilibrium indeterminacy. As in Jess Benhabib, Stephanie Schmitt-Grohé and Martín Uribe (2002), the model described above has multiple steady states to which equilibrium sequences may converge. There is an intended steady state with zero inflation. But there is also an unintended deflationary steady state, a permanent liquidity trap, in which $i=0$ and nominal prices fall at a rate $\beta_{h}-1<0$. Here, we follow Mertens and Ravn (2010a) and instead analyze temporary liquidity traps driven by a random sunspot variable that has no direct impact on fundamentals. We denote this variable $\psi_{t}$ and interpret it as measuring exogenous variation in aggregate confidence or sentiment. It follows a two-state Markov chain, $\psi_{t} \in\left\{\psi^{o}, \psi^{p}\right\}$ (optimism and pessimism), with transition probability matrix given by

$$
R=\left[\begin{array}{cc}
1 & 0 \\
1-q_{p} & q_{p}
\end{array}\right]
$$

where $q_{p}$ is the probability of the pessimistic state persisting. For simplicity, the optimistic state is absorbing. Assuming the zero lower bound on the nominal interest rate is binding in the pessimistic state, equilibrium dynamics are globally indeterminate. We restrict attention to equilibria in which all endogenous variables are functions of a minimal set of state variables (credit, entrepreneurial real estate and price dispersion) that also includes the binary confidence variable $\psi_{t}$. Mertens and Ravn (2010b) describe in detail the equilibrium definition and solution technique. Although the transitional dynamics are not unique, equilibrium sequences with zero interest rates all converge to the same point as long as the liquidity trap persists, i.e. $\psi_{t}=\psi^{p}$. In this paper, we focus on this liquidity trap limit point.

A period is one quarter. We set $\beta_{h}=0.99$ and $\beta_{e}=0.98$. We assume that $n_{h}=1 / 3$ in the intended steady state, and that $\kappa=2.65$ which implies a Frisch labor supply elasticity of 0.75 . We set the Calvo parameter $\xi=0.65$ and the retail goods price elasticity $\eta=10$. Following Iacoviello (2005), residential housing accounts for 80 percent of total housing and $v=0.03$. We calibrate $\zeta=0.75$, and, finally, we assume a benchmark value of the loan-to-value parameter $\mu=0.9$. The interest rate rule coefficient is 
$\phi_{\pi}=1.5$. Finally, we set $q_{p}=0.8$ such that the expected duration of the liquidity trap recession is 5 quarters.

\section{Liquidity Traps and Leverage}

The model entails a strong financial accelerator in a liquidity trap. Suppose that the economy witnesses a persistent drop in confidence (a wave of pessimism). If the confidence drop is sufficiently serious, the economy can find itself in a self-fulfilling recession that causes contractions in economic activity, credit flows and prices. To understand this, note that when households and entrepreneurs become pessimistic, they will lower their demand for goods and housing. Retailers, anticipating lower demand, reduce prices as well as production. With housing in fixed supply, real estate prices fall. The fall in real estate prices lowers entrepreneurs' collateral value, and since debt contracts are nominal, falling goods prices increase entrepreneurs' real debt burden. In combination, the feedback effects from financial markets and the falling demand for wholesale goods force entrepreneurs to reduce their demand for consumption goods and real estate, contributing to yet more declines in goods and house prices.

When these forces are mild, the central bank can prevent a crisis by lowering interest rates. More serious waves of pessimism become selffulfilling because of the zero lower bound on the nominal interest rate. In this case, deflationary expectations raise real interest rates and further increase households' desired savings. This fuels the bonfire of falling goods and real estate prices, which raises entrepreneurs' real debt burden and further tightens their collateral constraint. This vicious downward spiral of prices and credit conditions terminates only when the drop in household wealth eliminates household excess savings, the contraction in house prices is sufficient to convince households to hold the excess supply of housing and goods prices equate aggregate consumption to output. For the parameter values given above, we show in Mertens and Ravn (2010b) that, as long as agents stay pessimistic, the economy converges to a situation in which output is $3 \%$ below the intended level, there is $7 \%$ deflation and real house prices are $4 \%$ lower than in the intended steady-state.

Leverage plays an important role in determin- ing liquidity trap outcomes. In the model, leverage is parameterized by the loan-to-value parameter $\mu$ in the borrowing constraint of the entrepreneurs in (5). The left panel of Figure 1 shows the output loss in the temporary liquidity trap as a function of $\mu$ (in percentage deviation of intended steady state output levels). When $\mu$ is close to zero, there is no debt and no leverage in equilibrium. As a result, the credit channels, i.e. the debt deflation and house price collateral channels, do not affect the severity of the liquidity trap recession. In this case the output loss is around 1 percent per quarter which is approximately the same as in the standard New Keynesian model without real estate in Mertens and Ravn (2010a). As $\mu$ increases, the output losses grow larger but in a very nonlinear fashion. For example, when $\mu$ rises from zero to 80 percent, the output loss in the liquidity trap increases from 1 percent to 2 percent. However, an increase from the benchmark value of 90 percent to 95 percent increases the output loss from 3 to 4.5 percent. Thus, the drop in output is sensitive to the loan-to-value $\mu$, in particular when entrepreneurs are highly leveraged. These results indicate that financial accelerator effects are very strong in a liquidity trap. Financial innovation that raises leverage entails the cost of much stronger financial propagation in case of a liquidity trap recession.

The reason liquidity trap equilibria exist is that monetary policy follows an interest rate rule that is subject to the zero lower bound. There is always an unintended deflationary steady state as in Benhabib, Schmitt-Grohé and Uribe (2002). In our framework this corresponds to the case where $q_{p}=1$. For temporary liquidity traps, i.e. $q_{p}<1$, intertemporal substitution and forward looking price setting behavior lead to output losses that are much larger than the output difference between the intended and unintended steady states. The latter only arises because of inefficiencies associated with price dispersion. Liquidity trap equilibria do not exist for every value of $q_{p}$, however. There is a critical value $q_{p}^{*}$ of the expected duration of pessimistic beliefs such that liquidity traps only arise when $q_{p} \in\left(q_{p}^{*}, 1\right]$ This critical value will depend on the structural parameters of the model, including the loan-to-value parameter $\mu$. Leverage therefore determines the set of possible sunspots for which liquidity trap recessions can occur. 

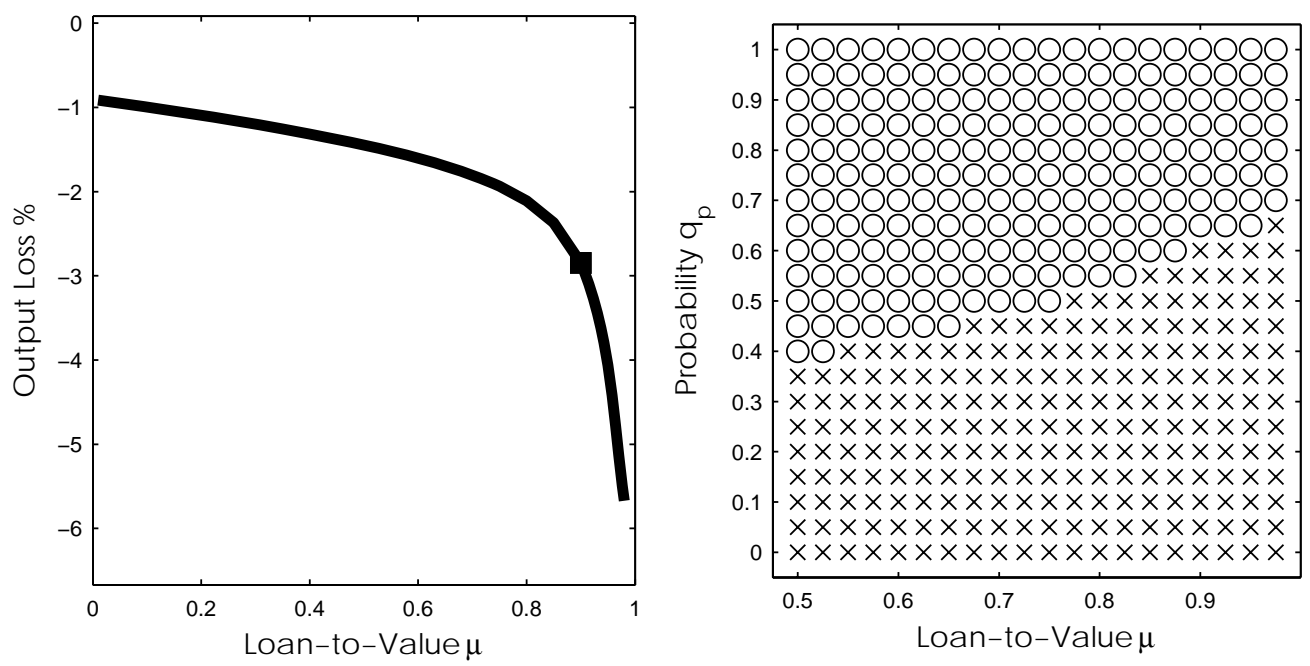

Leverage and Output in a Liquidity Trap

In the right panel of Figure 1, we illustrate with circles combinations of $\mu$ and $q_{p}$ for which expectations driven liquidity trap are possible, while crosses mark combinations of $\mu$ and $q_{p}$ for which they are not. The value of $q_{p}^{*}$, the border between the two regions, is increasing in loan-to-value $\mu$. Thus, higher leverage rules out less persistent expectations driven liquidity traps. However, as long as pessimism persists at least three quarters in expectation, the liquidity trap cannot be ruled out even for $\mu \rightarrow 1$. It is tempting to conclude that, since $q_{p}^{*}$ is increasing in $\mu$, higher leverage makes expectations driven liquidity traps less likely while raising their expected duration. This should however be taken with a grain of salt given that our model does not include a theory of the determinants of $q_{p}$.

\section{Conclusion}

We have examined a New Keynesian model with real estate and financial frictions in which expectations can drive the economy into a liquidity trap recession in which the financial accelerator is very large. Financial innovation that increases equilibrium leverage gives rise to more severe liquidity trap recessions and rules out short liquidity traps.

\section{References}

Benhabib, Jess, Schmitt-Grohé, Stephanie, and Uribe, Martín, 2002, "Avoiding Liquidity Traps”, Journal of Political Economy 110(3).
Iacoviello, Matteo, "House Prices, Borrowing Constraints, and Monetary Policy in the Business Cycle”, American Economic Review 95(3), 739-64.

Kiyotaki, Nobuhiro and John Moore, 1997, "Credit Cycles", Journal of Political Economy 105(2), 211-48.

Mertens, Karel and Morten O. Ravn, 2010a, "Fiscal Policy in an Expectations Driven Liquidity Trap”, CEPR Discussion Paper no. 7931.

Mertens, Karel and Morten O. Ravn, 2010b, “Credit Channels in a Liquidity Trap”, manuscript, Cornell University and University College London.

Sargent, Thomas J. and Neil Wallace, 1975, “'Rational Expectations', the Optimal Monetary Instrument, and the Optimal Money Supply Rule”, Journal of Political Economy 83, 241-54. 